\title{
Estresse oxidativo associado à prática de exercício físico com videogame ativo: Suplementação nutricional como fator antioxidante
}

\author{
Oxidative stress associated with physical exercise practice with active videogame: Nutritional \\ supplementation as an antioxidant factor
}

Estrés oxidativo asociado a la práctica de ejercicio físico con videojuego activo: Suplementación nutricional como factor antioxidante

Recebido: 12/04/2021 | Revisado: 19/04/2021 | Aceito: 23/04/2021 | Publicado: 08/05/2021

\author{
Rayli Maria Pereira da Silva \\ ORCID: https://orcid.org/0000-0002-7915-9553 \\ Centro Universitario UNIFACISA, Brasil \\ E-mail: raylipsilva@gmail.com \\ Mônica Oliveira da Silva Simões \\ ORCID: https://orcid.org/0000-0002-5803-599X \\ Universidade Estadual da Paraíba, Brasil \\ E-mail: monicasimoes.uepb@gmail.com \\ Anahi Cézar de Lima Lins \\ ORCID: https://orcid.org/0000-0003-2983-0051 \\ Universidade Estadual da Paraíba, Brasil \\ E-mail: anahicll@hotmail.com \\ Amanda Maria Guimarães Barros \\ ORCID: https://orcid.org/0000-0002-0963-4523 \\ Universidade Estadual da Paraíba, Brasil \\ E-mail: amanda.guiimaraes@hotmail.com \\ Shirley Pereira da Paiva Alves \\ ORCID: https://orcid.org/0000-0003-3090-6033 \\ Universidade Estadual da Paraíba, Brasil \\ E-mail: shirleynutricionista@gmail.com \\ Anna Larissa Veloso Guimarães \\ ORCID: https://orcid.org/0000-0003-4552-2948 \\ Universidade Estadual da Paraíba, Brasil \\ E-mail: annalariissa@gmail.com \\ Danielle Franklin de Carvalho \\ ORCID: https://orcid.org/0000-0003-4835-082X \\ Universidade Estadual da Paraíba, Brasil \\ E-mail: daniellefranklin6@gmail.com \\ Carla Campos Muniz Medeiros \\ ORCID: https://orcid.org/0000-0002-7994-7277 \\ Universidade Estadual da Paraíba, Brasil \\ E-mail: carlamunizmedeiros@hotmail.com
}

\begin{abstract}
Resumo
Objetivo: mostrar como os mecanismos antioxidantes ocorrem no corpo humano e investigar os parâmetros de estresse oxidativo e sua relação com o exercício físico, revelando pesquisas que indicam meios para evitar esse processo, tentando prevenir doenças que aparecem com a prática inadequada de exercícios. Métodos: o estudo se constitui numa revisão de literatura sobre estresse oxidativo associado à prática de exercícios, segundo a interpretação e análise crítica do próprio autor. Tal método de pesquisa envolve a síntese de artigos já publicados, permitindo construir a análise da literatura científica. As bases de dados utilizadas para a busca foram Bireme, medline, Scientific Eletronic Library Online (SciELO) e Pubmed. Resultados: Os resultados mostram que a prática regular de exercícios físicos associada a bons hábitos alimentares influencia na redução da prevalência de síndrome metabólica e aumento da concentração de glutationa e a proteção antioxidante total.Conclusão:exercícios físicos intensos e exaustivos promovem um desequilíbrio entre agentes oxidantes e antioxidantes e são os fatores mais importantes na formação do estresse oxidativo, a prática regular de exercícios físicos é considerada um fator de grande relevância na modulação do estresse oxidativo.
\end{abstract}

Palavras-chave: Estresse oxidativo; Radicais livres; Atividade física; Obesidade. 


\begin{abstract}
Objective: to show how the antioxidant mechanisms occur in the human body and to investigate the parameters of oxidative stress and its relationship with physical exercise, revealing researches that indicate ways to avoid this process, trying to prevent diseases that appear with the inadequate exercise practice. Methods: the study is a literature review on oxidative stress associated with exercise, according to the author's own interpretation and critical analysis. Such research method involves the synthesis of articles already published, allowing the construction of the analysis of the scientific literature. The databases used for the search were Bireme, medline, Scientific Electronic Library Online (SciELO) and Pubmed. Results: The results show that the regular practice of physical exercises associated with good eating habits influences in reducing the prevalence of metabolic syndrome and increasing the concentration of glutathione and the total antioxidant protection. Conclusion: intense and exhausting physical exercises promote an imbalance between oxidizing and antioxidant agents and are the most important factors in the formation of oxidative stress, the regular practice of physical exercises is considered a factor of great relevance in the modulation of oxidative stress.
\end{abstract}

Keywords: Oxidative stress; Free radicals; Physical activity; Obesity.

\begin{abstract}
Resumen
Objetivo: mostrar cómo se producen los mecanismos antioxidantes en el cuerpo humano e investigar los parámetros del estrés oxidativo y su relación con el ejercicio físico, revelando investigaciones que indican formas de evitar este proceso, tratando de prevenir enfermedades que aparecen con la práctica inadecuada de ejercicio. Métodos: el estudio es una revisión de la literatura sobre el estrés oxidativo asociado al ejercicio, de acuerdo con la interpretación y análisis crítico del propio autor. Dicho método de investigación implica la síntesis de artículos ya publicados, lo que permite la construcción del análisis de la literatura científica. Las bases de datos utilizadas para la búsqueda fueron Bireme, medline, Scientific Electronic Library Online (SciELO) y Pubmed. Resultados: Los resultados muestran que la práctica regular de ejercicios físicos asociados a los buenos hábitos alimentarios influye en la reducción de la prevalencia del síndrome metabólico y en el aumento de la concentración de glutatión y la protección antioxidante total. Conclusión: los ejercicios físicos intensos y agotadores promueven un desequilibrio entre agentes oxidantes y antioxidantes y son los factores más importantes en la formación del estrés oxidativo, la práctica regular de ejercicios físicos se considera un factor de gran relevancia en la modulación del estrés oxidativo.
\end{abstract}

Palabras clave: Estrés oxidativo; Radicales libres; Actividad física; Obesidad.

\title{
1. Introdução
}

As doenças crônicas não transmissíveis (DCNT), são as principais causas de morbimortalidade em países desenvolvidos e em desenvolvimento como o Brasil. As principais são as doenças cardiovasculares, respiratórias crônicas, diabetes mellitus e neoplasias. Dentre os fatores de riscos estão atividade física insuficiente, tabagismo, alimentação não saudável e o uso nocivo do álcool (Brasil, 2011).

Dentre os mecanismos relacionados a patogênese das DCNT, estão as alterações no metabolismo oxidativo, esta indica uma associação entre a quebra da homeostasia do metabolismo oxidativo e o aumento das DCNT. Cerca de 5\% do oxigênio utilizados pelos organismos, não é utilizado nos ciclos mitocondriais que produzem energia, esse oxigênio excedente tende a perder dois elétrons em sua última camada, produzindo o radical superóxido ou por ações enzimáticas e metabólicas podem formar outros tipos de moléculas desemparelhadas de oxigênio, que são genericamente conhecidas como espécies reativas de oxigênio (EROs) (Gottlieb, Morassutti\& Cruz, 2014).

As EROs são parte integrante do metabolismo normal e são observadas em diversas condições fisiológicas causando danos: a peroxidação de lipídios de membrana, oxidação de receptores hormonais e enzimas, como também lesão no material genético das bases do DNA que podem culminar em processos mutagênicos e tumorais. As espécies reativas são átomos, moléculas ou íons derivados do oxigênio, que possuem alta reatividade e constituem três classes de compostos: espécies reativas de oxigênio (EROs), espécies reativas de enxofre (EREs) e espécies reativas de nitrogênio (ERNs). Podem ser divididas em dois grupos, os radicais livres e os compostos não radicalares que são o peróxido de hidrogênio $\left(\mathrm{H}_{2} \mathrm{O}_{2}\right)$ e ácido hipocloroso (HOCL). A produção dos radicais livres pode acarretar inúmeras maneiras de dano celular e podem estar envolvidas com o aparecimento das DCNT (Martelli \& Nunes, 2014). 
O organismo é responsável por controlar a degradação dos radicais livres através do sistema antioxidante endógeno enzimático, por serem moléculas altamente reativas, nas quais há a degradação do superóxido em água e em um outro sistema exógeno não enzimático, quando compostos antioxidantes presentes na dieta atuam sobre as EROs produzidas pelo organismo. O desequilíbrio entre compostos oxidantes e antioxidantes desencadeia o processo chamado estresse oxidativo (Viña, Bonas\& Gomes-Cabrera, 2018).

A inatividade física é considerada um fator de risco importante para o desenvolvimento de doenças crônicas. O exercício físico é responsável por promover saúde e bem-estar, quando realizado em intensidade moderada são conhecidos por não induzirem ou diminuir um estado pró-oxidativo e pró-inflamatório, além de reforçar as defesas antioxidantes via adaptação ao estresse oxidativo, porém a alta atividade muscular leva a um aumento a produção das EROs por meio do acréscimo do consumo de oxigênio mitocondrial nos tecidos (França, Sousa \& Marques, 2017).

Com o intuito de reduzir os efeitos oxidantes promovidos pelo exercício extenuante, algumas alternativas nutricionais têm sido estudadas como a suplementação como ß-caroteno, vitamina A, C e E, cretatina, glutamina, ômega-3, selênio e zinco (Francisqueti et al., 2017).

O objetivo do trabalho baseia-se em demonstrar como os mecanismos antioxidantes ocorrem no corpo e investigar os parâmetros de estresse oxidativo e sua relação com o exercício físico, revelando pesquisas que indicam meios para evitar esse processo, tentando prevenir doenças que aparecem com a prática inadequada de exercícios e nutrição que estão relacionadas com as espécies reativas de oxigênio.

\section{Metodologia}

O estudo se constitui numa revisão de literatura sobre estresse oxidativo associado à prática de exercícios, segundo a interpretação e análise crítica do próprio autor. Tal método de pesquisa envolve a síntese de artigos já publicados, permitindo construir a análise da literatura científica. Para tanto foram consultados artigos de periódicos e dissertações.

As bases de dados utilizadas para a busca foram Bireme, medline, Scientific Eletronic Library Online (SciELO) e Pubmed, .

Os critérios de inclusão adotados foram: artigos de pesquisa originais, artigos completos disponíveis; idioma português, espanhol ou inglês; publicados entre 2015 - 2021, e aqueles que contribuíssem para a temática relativa aos aspectos relacionados ao estresse oxidativo e a prática de exercícios. Os critérios de exclusão foram: editoriais, relatórios e comentários. Durante as bucas e aplicação dos critérios de elegibilidade, nenhum artigo do ano 2021 foi selecionado para a revisão.

Foram realizadas busca eletrônica nas bases de dados através dos descritores utilizados selecionados mediante consulta prévia ao Medical SubjectHeadings (MeSH) e ao Descritores em Ciências da Saúde (DeCS). Os descritores utilizados para a busca nas bases de dados Scielo e Bireme corresponderam a: "estresse oxidativo"/ "oxidative stress", "exercício físico"/ "exercisephysical", "radicais livres de oxigênio"/ "oxygenfreeradicals", "antioxidantes"/ "antioxidants" e "suplementação"/ "supplementation".

A expressão Booleana AND foi utilizada para realizar o cruzamento nas duas bases de dados utilizadas: "estresse oxidativo" AND "exercício físico", "estresse oxidativo" AND "radicais livres de oxigênio", "estresse oxidativo" AND "antioxidantes" e "antioxidantes" AND "suplementação".

Posteriormente foi realizada a análise dos títulos e resumos dos artigos científicos identificados através da busca eletrônica, podendo-se assim julgar a pertinência dos estudos à temática da revisão e aqueles que não atenderam aos critérios de inclusão. Por fim realizou-se a leitura na íntegra de todos os artigos considerados elegíveis para inclusão na revisão. 


\section{Resultados e Discussão}

\section{Radicais livres e o estresse oxidativo}

Habitualmente é nas mitocôndrias, membranas celulares e no citoplasma que ocorrem os mecanismos de geração de radicais livres - átomos ou moléculas que apresentam um ou mais elétrons não-pareados - formadas pela respiração celular. Tais mecanismos podem, principalmente, ser favorecidos pelos íons ferro e cobre. A mitocôndria é a principal fonte geradora de radicais livres por meio da cadeia transportadora de elétrons (Georgieva et al., 2017).

Os radicais livres de oxigênio (RLOs) mais comuns no corpo humano, decorrentes de algumas alterações celulares, são o ânion radical superóxido, a radical hidroxila e o radical hidroperoxil, enquanto as espécies não radicalares mais comuns são peróxido de hidrogênio e oxigênio singleto $(\mathrm{O} 2)$, que é formado por fotoindução do $\mathrm{O} 2$ nos organismos vivos. Porém, o excesso de EROs em nosso corpo nem sempre é maléfico, mesmo sendo considerado prejudicial à saúde, devido ao fato de algumas delas serem essenciais em processos vitais (Leite, Brasil, Marques \& Catão, 2015).

No entanto, a existência de um desequilíbrio entre compostos oxidantes e antioxidantes, em favor da geração excessiva de radicais livres ou em detrimento da velocidade de remoção desses, dá origem a instalação do processo chamado estresse oxidativo. Este processo leva à oxidação de biomoléculas com consequente perda de suas funções biológicas e/ou desequilíbrio homeostático, cuja manifestação é o dano oxidativo potencial contra células e tecidos (Georgievaet al., 2017).

O estresse oxidativo desencadeia alterações dos lipídeos conhecida como peroxidação lipídica, além de danos oxidativos no DNA e proteínas (grupos carbonilas e sulfidrilas). Além disso a peroxidação lipídica modifica a fluidez das membranas, ocasionando menor seletividade no transporte iônico e na sinalização transmembrana, o que interfere no transporte celular (Viñaet al., 2018).

Os radicais livres podem ser produzidos a partir das interações metabólicas, sendo de origem endógena, através das mitocôndrias ou por condições ambientais, de origem exógena. Nos sistemas biológicos tem-se o oxigênio como fonte primordial de radicais livres, o qual é reduzido em etapas sequenciais para produzir água sendo fundamental para geração de energia e mecanismos celulares (Georgieva et al., 2017).

Sabe-se que os radicais livres são considerados fatores causadores de lesões no exercício físico, no entanto, desempenham funções metabólicas essenciais e efeitos positivos no sistema imunológico. A ação deletérica ou benéfica dos radicais livres no organismo depende da atividade dos antioxidantes, que executam uma atuação supressora dos radicais e seus efeitos nocivos. Sendo assim, o processo de geração do estresse oxidativo se dá quando a ação dos antioxidantes é superada pela atividade dos radicais livres (Martelli \& Nunes, 2014).

O processo de estresse oxidativo (EO) está associado a danos musculares e disfunções metabólicas e, consequentemente, redução do desempenho físico, sendo desencadeado pelo desequilíbrio entre produção e remoção das ERO. Considerando aspectos da biologia molecular, especula-se a participação das ERO como fator causal de agravos do músculo esquelético (Sies, 2015).

O EO provoca também alterações no funcionamento fisiológico de diversos órgãos, dentre eles o fígado e o coração, nos quais é identificado apresentação de alta taxa metabólica associada ao alto fluxo de elétrons na cadeia respiratória mitocondrial e consequente elevada produção de EROs (Kaim \& Backes, 2019).

As Espécies Reativas de Oxigênio (ERO) e Espécies Reativas de Nitrogênio (ERN) por fazerem parte do metabolismo celular exercem diversas funções fundamentais, como atividades microbicidas, sinalização e biogênese celular. Porém, elas desenvolvem um processo conhecido como peroxidação lipídica (PL), considerado principal fator indutor deste processo de ativação em cadeia, por apresentarem uma configuração eletrônica instável e por serem reativas. A PL trata-se de danos a proteínas e, especialmente, aos fosfolipídios de membranas celulares, tendo por consequência alteração do balanço hídrico da célula e oxidação de compostos tióis, cofatores enzimáticos, nucleotídeos e DNA (Vasques \& Fonseca, 2018). 
A capacidade antioxidante total pode ser considerada um marcador de estresse oxidativo, visto que mede o estado da capacidade antioxidante em fluidos biológicos. Trata-se de um método responsável por proporcionar uma visão mais profunda do envolvimento do estresse oxidativo em diversas condições fisiopatológicas, bem como monitorar a eficácia das intervenções antioxidantes (Francisqueti et al., 2017).

Baseado nisso, diversas alterações em células hepáticas e cardíacas são ocasionadas pelo estresse oxidativo, podendo levar ao surgimento de doenças como esteatose hepática, hepatite $\mathrm{C}$ e aterosclerose. Contudo, quando o treinamento físico é desenvolvido de maneira bem planejada, pode melhorar tanto os mecanismos de defesa antioxidantes como a capacidade oxidativa do tecido, podendo levar a diminuição da magnitude do ataque oxidativo e desta forma, prevenir efeitos deletérios decorrentes do mesmo (Kaim \& Backes, 2019).

\section{O exercício físico e o estresse oxidativo}

O exercício físico gera benefícios à saúde em geral e na prevenção de doenças bastante conhecidas. No entanto, o exercício crônico caracteriza uma forma de estresse oxidativo para o organismo podendo provocar alterações no balanço entre oxidantes e antioxidantes (Vasques \& Fonseca, 2018).

Presumia-se que a síntese de radicais livres no exercício físico tinha somente efeitos deletérios para o organismo. Porém, atualmente é confirmado que níveis baixos dos radicais livres encontrados na musculatura durante repouso podem indicar etapas da concentração normal (França et al., 2017).

A prática de exercício aumenta a produção de estresse oxidativo. No entanto, esse aumento parece ser primordial para possibilitar uma regulação positiva nas defesas antioxidantes endógenas, viabilizando os efeitos benéficos para o indivíduo que realiza o exercício (Francisqueti et al., 2017).

De acordo com a literatura, o esforço que supera a capacidade funcional do indivíduo, chamado de exercício físico estressante, leva a um aumento significativo do consumo e utilização muscular do oxigênio. Desta forma, impulsionando a produção mitocondrial das espécies reativas de oxigênio, lesão às macromoléculas e maior nível de estresse oxidativo, sendo determinado pela diminuição das defesas antioxidantes, maior consumo de $\mathrm{O} 2$ e menor eficácia da respiração mitocondrial (Sies, 2015).

O músculo esquelético é um tecido altamente elástico que sofre mudanças consideráveis em resposta ao exercício de resistência e treinamento, notavelmente em apenas 5-10 dias consecutivos de exercício de resistência resulta em aumentos substanciais na capacidade oxidativa e antioxidante nas fibras do músculo esquelético (Powers et al., 2020).

Nessa conjuntura, a dor é resultante comprometimento da função muscular e da ressintetização do glicogênio muscular após a lesão tecidual inicial, têm relevância para indivíduo relativamente sedentário no início de um programa de exercícios, para um exercitador habitual que planeja uma única atividade além do regime habitual e / ou um atleta que retorna ao esporte após uma lesão. Esses indivíduos se beneficiarão de intervenções antioxidantes para aliviar esses sintomas, seja para facilitar a aderência a um programa de exercicios ou para compensar redução no desempenho (Fernandes, Araújo, Trigo \& Pussieldi, 2017).

O dano tecidual e a ocorrência do estresse oxidativo decorre da prática de exercícios exaustivos ou de duração prolongada, uma vez que o exercício aumenta o consumo de oxigênio e causa um distúrbio na homeostase pró e antioxidante intracelular. $\mathrm{O}$ treinamento físico é importante na prevenção parcial da formação de radicais livres (RL) no exercício extenuante e aumenta as defesas antioxidantes (AO) (Pizzino et al., 2017).

O exercício coloca um grau de estresse mecânico e metabólico no corpo, que contribuem conjuntamente para uma resposta patológica subclínica comum envolvendo estresse oxidativo e subsequente inflação (Fernandes et al., 2017). 
Tem sido observado que, independentemente do nível de performance, é comum a ocorrência de lesões musculares como contusões e estiramentos, que têm sido observadas como as mais frequentes nos esportes, sendo comuns no âmbito clínico e representando 90\% do total de casos (Leite et al., 2015).

Os fatores biomecânicos destacam-se dentre os responsáveis pela ocorrência dessas lesões, caracterizados por resultantes de força que excedem a capacidade estrutural do tecido muscular, bem como os fatores fisiológicos, relacionados à instalação de fadiga, determinados por resultantes de reações bioquímicas associadas ao exercício (Leite et al., 2015).

No momento em que o fornecimento de energia passa a exceder a capacidade de armazenamento de adipócitos e, como resultado, acontece hipertrofia, se desencadeia o processo de inflamação e estresse oxidativo. Em consequência da hipertrofia, ocorre uma maior liberação de adipocinas como citocinas pró-inflamatórias, como interleucina-1 (IL-1) interleucina-6 (IL-6) e fator de necrose tumoral alfa (TNF- $\alpha$ ), ocasionando inflamação crônica de baixo grau, que inicia no tecido adiposo e, possivelmente, atinge a circulação e outros órgãos resultando em resistência à insulina, visto que o TNF- $\alpha$ impede a fosforilação dos receptores de insulina (Vasques \& Fonseca, 2018).

Estudos mostram que a prática regular de exercícios físicos associada a bons hábitos alimentares influencia na redução da adiposidade visceral, reduzindo a prevalência de síndrome metabólica e aumentando, especialmente, a concentração significativa de glutationa e a proteção antioxidante total (TAP) do plasma (Vasques \& Fonseca, 2018).

Existem evidências crescentes de que o exercício e treinamento exaustivo agudo ocasionam o aumento da necessidade de vitaminas antioxidantes. De fato, algumas vitaminas (vitamina E, vitamina C,beta-caroteno e retinol) neutralizam várias EROs e também desempenham importante função no estresse oxidativo induzido pelo exercício. Dessa forma, a ingestão frequente de vitaminas antioxidantes por atletas treinados deve ser suficiente para suprir as necessidades adicionais induzidas pelo treinamento ou por uma competição (França et al., 2017).

\section{Mecanismo de defesa antioxidante}

Os antioxidantes são conceituados como qualquer substância que, existente em menores concentrações que as do substrato oxidável, seja capaz de retardar ou inibir a oxidação deste de forma eficaz. A grande variedade de susbstâncias antioxidantes podem ter origem endógena ou dietética (Georgieva et al., 2017)

Os antioxidantes estão envolvidos na sinalização redox das células, existem enzimas antioxidantes, como superóxido dismutase, catalase, glutationaperoxidase, glutationaredutase - responsáveis pelo sistema de defesa enzimático e fundamentais para o controle de sinalização redox; além disso, compostos exógenos com propriedades antioxidantes como, polifenóis, vitamina $\mathrm{C}$ e vitamina $\mathrm{E}$, que são encontrados na alimentação podem interagir na rede redoxe compostos do sistema nãoenzimáticos tais como ferritina, transferrina, bilirrubina, ceruloplasmina e até mesmo portador de albumina de baixo peso molecular, como ácido úrico e ácido lipóico, que são responsáveis pelo sistema de defesa antioxidante endógeno que desempenham papel fundamental no controle do estresse oxidativo (Mason et al., 2020).

Considerando que desequilíbrio entre o sistema de defesa antioxidante e a geração de radicais livres é uma circunstância que desencadeia o estresse oxidativo, devido a esse fator é ocasionado a liberação destes radicais livres. A produção contínua dos radicais durante os processos metabólicos culmina no desenvolvimento de mecanismos de defesa antioxidante. Sendo assim, a teoria antioxidante parte do pressuposto que essa geração contínua de radicais, devido à fosforilação oxidativa efetivamente acoplada, destrói continuamente as mitocôndrias com ataques oxidativos (França et al., 2017).

Algumas evidências revelam os benefícios da prática contínua de exercícios físicos, tanto em pessoas saudáveis como em portadores de doenças como diabetes mellitus, asma, obesidade, hipertensão, artroses e artrites, porém ainda existem resultados controversos quanto aos efeitos dos exercícios no cérebro. Provavelmente, o excesso de formação de radicais livres 
desencadeia o acréscimo da atividade de enzimas antioxidantes no cérebro como resposta ao exercício físico regular (Francisqueti et al., 2017).

Nessa conjuntura, a realização de uma série aguda de exercícios pode levar ao aumento da atividade de algumas enzimas antioxidantes sem uma nova síntese protéica. Este sistema de proteção é restrito a características enzimáticas individuais e o tecido envolvido. Conseguinte, as células podem elevar a síntese protéica de enzimas antioxidantes para monitorar o estresse oxidativo, como estratégia a longo prazo (Francisqueti et al., 2017).

Os antioxidantes são capazes de agrupar radicais livres gerados pelo metabolismo celular ou fontes exógenas através da doação de átomos de hidrogênio dessas moléculas, rompendo a reação em cadeia e evitando assim a formação de lesões e perda de integridade celular. Outra função dos antioxidantes é desenvolver um mecanismo de proteção, atuando no reparo dos danos causados pelos radicais livres, um processo relacionado à remoção dos danos a molécula de DNA e restauração de membranas celulares danificadas (Vasques \& Fonseca, 2018).

O consumo de oxigênio para produção aeróbia de adenosina trifosfato (ATP), que ocorre durante o exercício, pode aumentar de 10 a 20 vezes em relação aos níveis de repouso e até 100 vezes em nível muscular, levando a uma elevação concomitante na produção das Espécies Reativas de Oxigênio (ERO) e em consequência deste processo gera danos oxidativos na estrutura celular pela oxidação de lipídeos de membrana, carbonilação de proteínas, oxidação de carboidratos e danos em ácidos nucléicos (Fernandes et al., 2017).

\section{A influência da suplementação nutricional como fator antioxidante}

Frente ao estresse oxidativo, promovido durante exercícios físicos, as células podem se defender devido à atuação dos diversos tipos de antioxidantes celulares. Precisamente por causa dos eficientes sistemas antioxidantes celulares e também daqueles provenientes da alimentação. Estudos têm apontado que o sistema de defesa antioxidante pode ser influenciado por nutrientes específicos (Pizzino et al., 2017).

Com o intuito de reduzir os efeitos oxidantes promovidos pelo exercício extenuante, algumas alternativas nutricionais têm sido estudadas, dentre elas a suplementação com vitamina E, vitamina C, creatina e glutamina. No entanto, para estimular as defesas antioxidantes do organismo outra estratégia utilizada é a suplementação com ômega-3, - ácido graxo poli-insaturado de cadeia longa, que tem mostrado ação anti-inflamatória eficiente estimulada pela diminuição da síntese de potentes mediadores químicos da inflamação derivados do ácido araquidônico, ou seja, prostaglandina E2 (PGE2), tromboxano A2 (TXA2), prostaciclina (PGI2) e leucotrieno B4 (LTB4) (Becker, Pereira, Pena \& Silva, 2016).

Um fator interveniente na resposta antioxidante e as manifestações de síndrome metabólica é a associação entre adequação dietética e exercício físico. Esse fato é devido aos antioxidantes exógenos e endógenos que atuam em sinergia no combate aos radicais livres. No entanto, é importante ressaltar que essa ingestão deve ser realizada de forma adequadas (Vasques \& Fonseca, 2018).

Os alimentos conhecidos como funcionais são aqueles que ao serem ingeridos nas dietas, além das suas funções nutricionais, desempenham alguns efeitos metabólicos e fisiológicos no organismo, através do desemprenho de algum nutriente, principalmente, a atuação em algumas patologias. Entretanto, para que sejam eficazes faz-se necessário o uso regular e associação ao consumo de frutas, verduras, cereais integrais, carne, leite de soja e alimentos ricos em ômega-3, conhecida como dieta mediterrânea. Os antioxidantes exógenos de frutas e vegetais, incluindo hidrofílico como vitamina C e flavonóides e lipofílico como vitamina E ecarotenóides são responsáveis por dar funcionalidade aos alimentos (Becker et al., 2016).

Dessa forma, a dieta é um fator de grande relevância na modulação do estresse oxidativo. Quando se desenvolve um desequilíbrio entre o provimento de nutrientes e uma redução da ingestão de antioxidantes, o excesso de peso/obesidade pode acarretar numa síndrome metabólica promotora do estresse oxidativo (Becker et al., 2016). 
Os estudos de suplementação têm conseguido demonstrar efeitos positivos sobre biomarcadores específicos, sendo os relacionados à oxidação de lipídeos (malondialdeído e isoprostanos) os de maior relevância, apesar dos efeitos da suplementação de vitaminas e minerais antioxidantes sobre o estresse oxidativo não serem ainda conclusivos, principalmente em relação à dose e ao tempo de suplementação (Gasparovik, 2017).

Do ponto de vista biológico, os antioxidantes podem ser definidos como substâncias responsáveis pela inibição e redução das lesões causadas pelos radicais livres. Entre os antioxidantes podem ser citados: resveratrol e quercetina, antoxantina, antocianina, fitoestrógenos, flavonoides, taninos, zeaxantina. E do grupo de carotenoides destacam-se: betacaroteno, licopeno e luteína. Constituindo outra classe de compostos funcionais atuantes na estimulação do sistema imunológico (Laurent \& Alain, 2017).

De acordo com Laurent e Alain (2017), alguns nutrientes específicos atuam no sistema de defesa antioxidante, tais como: a vitamina E, um dos antioxidantes mais abundantes na natureza, atuando sobre a membrana da célula e com função protetora contra a peroxidação lipídica (PL) reagindo diretamente com radicais de $\mathrm{O}_{2}$; o ácido ascórbico (Vitamina C), que é uma vitamina hidrossolúvel possui funções antioxidantes, atenuando o estresse oxidativo e a PL induzida pelo exercício físico; o zinco, tem importante função na proteção antioxidante celular ligado a diversos mecanismos de combate as EROs, a menor disponibilidade deste mineral permite que o quadro de estresse oxidativo crônico ocorra, fato que influencia a capacidade de defesa imunológica do organismo.

A suplementação com compostos multivitamínicos minerais antioxidantes atenua a PL, induzida por exercícios extenuantes; os flavonoides facilitam o sequestro de oxi-radicais e atuam no combate ao estresse oxidativo em indivíduos atletas ou mesmo em estados patológicos; o consumo de creatina pode resultar em ganho de força, massa muscular e melhorar o desempenho físico, gerando maior capacidade de recuperação muscular, implicando em menor quantidade de lesões e processo inflamatório, aumentando a resistência da célula, a glutamina desempenha importante ação moduladora sobre vias de sinalização celular, relacionando-se com a expressão de genes envolvidos com a síntese e degradação de proteínas, regula fatores de crescimento, resposta inflamatória e imunológica, proliferação e apoptose celular (Laurent \& Alain, 2017).

Estudos anteriores forneceram evidências de efeitos benéficos da suplementação de vitamina $\mathrm{C}$ por duas semanas em relação às mudanças na função / dor muscular e em certos aspectos do estresse oxidativo (ou seja, a peroxidação lipídica) e inflamação (ou seja, a resposta das citoquinas) após a realização de exercícios intermitentes (Vieira, Souza, Oliveira \& PaesSilva, 2018).

O benefício da vitamina $\mathrm{C}$ isoladamente, em consistência com outros estudos apresentam recuperação melhorada da contração voluntária máxima e evidências de redução da peroxidação lipídica após danos musculares induzidos pelo exercício. Além dos efeitos da ingestão de antioxidantes únicos, estudos mais recentes exploraram os benefícios potenciais de antioxidantes mistos - produtos comerciais populares. No entanto a maioria dos estudos não informa sobre o efeito da suplementação combinada de vitamina C e E sobre as respostas sistêmicas de citocinas após o exercício (Vieira et al., 2018).

\section{Excesso de peso e exercício físico com videogame ativo}

Com o corrente processo de transição nutricional, o sobrepeso e a obesidade são encontrados com grande frequência, a partir de 5 anos de idade, em todos os grupos de renda e em todas as regiões brasileiras. Sendo a obesidade considerada uma Doença Crônica Não-Transmissível (DCNT), multifatorial e universal de prevalência crescente que vem alcançando proporções alarmantes, contribui para o desenvolvimento de várias outras morbidades, provocando forte impacto na saúde pública da sociedade moderna (Fernandes et al., 2017).

O Estresse oxidativo desempenha um papel muito importante no desenvolvimento e progressão de algumas doenças, porem é importante ressaltar que o treino regular de exercícios reduz a prevalência delas, o treinamento sobre o risco dessas 
patologias é foco de estudos, e muitos concluem que atividade física proporciona o aumento do fluxo cerebral e antioxidantes, dado que o exercício regular demonstrou reduzir o risco de vários tipos de câncer, doenças cardiovasculares, hipertensão, Alzheimer e Parkinson (Powers et al., 2020).

Algumas atividades sedentárias de lazer comuns nos estágios iniciais da vida, como utilizar computador e assistir televisão, além do uso de videogames e exposição excessiva a outras telas levam a inatividade física. Este tipo de comportamento, em longo prazo, pode desencadear e/ou agravar morbidades, como sobrepeso e obesidade, hipertensão e diabetes tipo 2 (Silva et al., 2015).

Deste modo, a inatividade física é considerada um fator de risco importante para o desenvolvimento de doenças crônicas. A prática regular de exercícios físicos torna-se essencial por prevenir o ganho excessivo de peso e a obesidade. No entanto, mesmo tendo seus benefícios reconhecidos, cerca de $70 \%$ da população adulta não atinge o nível mínimo de atividade física recomendada de no mínimo de 150 minutos semanais de atividade física, considerado seu lazer, trabalho e deslocamento (Fernandes et al., 2017).

Há algum tempo o videogame era enquadrado como um tipo de atividade sedentária, considerada prejudicial para a saúde dos jogadores por haver um período de inatividade durante as partidas. Contudo, o avanço tecnológico propiciou o desenvolvimento de videogames mais ativos, desencadeando maior interação entre o indivíduo e o aparelho eletrônico (Silva et al., 2015).

O videogame ativo (VGA), também chamado de exergame é um tipo de vídeo game no qual é utilizado um sensor que induz o jogador a realizar movimentos corporais, promovendo o aumento do nível de atividade física, que não se obtém com o uso do vídeo game sedentário (VGS). Após ser observado melhora no nível de atividade física, o VGA passou a ser indicado no tratamento de doenças como a obesidade e durante a reabilitação cardíaca após AVC, bem como em casos de pessoas com limitações, apresentando melhor equilíbrio em idosos (Melo et al., 2016).

Dessa forma, é possível alcançar resultados na aptidão física de uma pessoa através de atividades regulares, planejadas e estruturadas com videogame ativo.Entretanto, apesar da utilização dos VGAs terem efeitos no estado nutricional e cardiometabólico dos indivíduos a adesão de participantes de um programa de "tratamento" da obesidade é um grande desafio porque esta é uma doença de natureza multifatorial e por este motivo torna-se extremamente difícil uma intervenção que consiga abranger todos os elementos que a envolvem.Nesse sentido, o exercício físico promove importantes benefícios para a saúde, atuando na melhoria da aptidão cardiorrespiratória, da composição corporal e do bem-estar psicossocial, sendo amplamente utilizado como ferramenta primordial na prevenção e tratamento da obesidade e diversas morbidades (Fidelix et al., 2015).

\section{Conclusão}

É possível observar que os exercícios físicos intensos e de longa duração ou exaustivos promovem um desequilíbrio entre agentes oxidantes e antioxidantes e são os fatores mais importantes na formação do estresse oxidativo, e consequentemente na exposição a um maior fluxo de oxigênio. No entanto, a prática regular de exercícios físicos se torna essencial sendo considerada um fator de grande relevância na modulação do estresse oxidativo. Ainda é destituído de informações com base científica a respeito da utilização de alguns suplementos alimentares com o intuito de atenuar o estresse oxidativo, a respeito de seus reais efeitos, posologia e doses adequadas. A maioria dos trabalhos ainda apresentam que a forma mais eficaz de elevar as defesas antioxidantes do organismo é a partir da indução do aumento da síntese de espécies reativas mediante adequada periodização do treinamento e alimentação. 


\section{Referências}

Becker, L. K., Pereira, A. N., Pena, G. E., Oliveira, E. C., \& Silva, M. E. (2016). Efeitos da suplementação nutricional sobre a composição corporal e o desempenho de atletas: uma revisão. Revista Brasileira de Nutrição Esportiva, 10(55). 93-111.

Fernandes, R. L., Araújo, J. R., Trigo, R. W. M., \& Pussieldi, G. A. (2017). Relação entre estresse oxidativo, atividade física e desempenho escolar em adolescentes. ArqCien Esp;5(2):37-39.

Fidelix, Y. L., Farias Júnior, J. C., Lofrano-Prado, M. C., Guerra, R. L. F., Cardel, M., \& Prado, W. L. Multidisciplinary intervention in obese adolescents: predictors of dropout. Einstein. 2015; 13 (3): 388-94.

Francisqueti, F. V., Chiaverini, L. C. T., Santos, K. C., Minatel, I. G., Ronchi, C. B., Ferron, A. J. T., Ferreira, A. L. A., \& Corrêa, C. R. (2017). The role of oxidative stress on the pathophysiology of metabolic syndrome. Ver assoc Med Bras. 63(1): 85-91.

França, M. L., Souza, S. S., \& Marques, N. S. F. (2017). Benefícios da prática de exercício físico em pacientes com síndrome metabólica. DECiência em Foco; $1(1): 30-47$.

Gasparovik, A. C., Zarkovic, N., Zarkivic, K., Semen, K., Kaminskyy, D., Yelisyeyeva, O., \& Bottari, S. P. (2017). Biomarkers of oxidatixe stress: conventional and novel approaches. British Journal of Pharmacology 174 1771-1783.

Georgieva, E., Ivanova, D., Zhelev, Z., Bakalova, R., Gulubova, M., \& Aoki, I. (2017). Mitochondrial Dysfunction and Redox Imbalance as a Diagnostic Marker of "Free Radical Diseases". Anticancer Research October vol. 37 n. 10 5373-5381.

Gottlieb, M. G. V., Morassutti, A. L., \& Cruz, I. B. M. (2011). Transição epidemiológica, estresse oxidativo e doenças crônicas não transmissíveis sob uma perspectiva evolutiva. Sci Med.;21(2):69-80.

Kaim, M., Backes, L. T. H. (2019). Envelhecimento celular: teorias e mecanismos. Revista saúde integrada, 12(23).

Laurent, B., \& Alain, D. (2017). Antioxidants, mechanisms, and recovery by membrane processes, Critical Reviews in Food Science and Nutrition, 57:4, 677700 .

Leite, L. M. G. S., Brasil, R. L. F., Marques, T. M. A., Cruz, J. B., \& Catão, C. D. S. (2015). Estresse oxidativo e envelhecimento humano: uma revisão sistemática. Anais IV CIEH: Realize Editora.

Martelli, F., \&Nunes, F. M. F. (2014). Radicais livres: em busca do equilíbrio. Cienc. Cult. 66(3).

Mason, S. A., Trewin A. J., Parker, L., \& Wadley, G. D. (2020). Antioxidant supplements and endurance exercise: Current evidence and mechanistic insights. Redox Biology 35 (2020) 101471.

Melo, R. J. P., Garrido, N. D., Oliveira, S. F., Guimarães, F. J. S. P., \& Costa, M. C. (2016). Efeito do treinamento com videogames ativos nas dimensões morfológica e funcional: estudo clínico randomizado. Rev Motricidade. 12 (2): 70-79.

Ministério da Saúde. (2011). Plano de ações estratégicas para o enfrentamento das doenças crônicas não transmissíveis (DCNT) no Brasil 20112022. Secretaria de Vigilância em Saúde. Departamento de Análise de Situação de Saúde: Ministério da Saúde, 2011.

Pizzino, G., Irrera, N., Cucimotta, M., Pallio, G., Mannino, F., Arcoraci, V., Squadrito, F., Altavilla, D., \& Bitto, A. (2017). Oxidative Stress: Harms and Benefits for Human Health. Oxid Med Cell Longev.8416763.

Powers, S. K., Deminice, R., Ozdemir M., Yoshihara T., Bomkamp, M. P., \& Hyatt, H. (2020). Exercise-induced oxidative stress: Friend or foe?. Journal of Sport and Health Science 9 (2020) 415_425.

Sies H. (2015). Oxidative stress: a concept in redox biology and medicine Redox Biol. 4: 180-183.

Silva, T. F., Souza, M. S. C., Souza, M. F., Bastos, V. M. L., Veloso-Neto, G., \& Silva, A. S. (2015). Dispendio Energético do Vídeo Game Ativo pode ser suficiente como Exercício Físico para o Tratamento da Hipertensão Arterial: Estudo Piloto. Rev Brasileira de Ciências da Saúde. 19 (2): $59-66$.

Vasques, M. A. A., \& Fonseca, E. B. M. (2018). Estresse oxidativo, exercício físico e saúde encefálica. Rev Med Saude Brasilia; 7(1):76-98.

Vieira, E. C. M., Souza, T. K. M., Oliveira, M. T. T., \& Paes-Silva, R. P. (2018). Consumo de vitaminas antioxidantes e frequência de infecções do trato respiratório superior em praticantes de musculação. Revista Brasileira de Nutrição Esportiva, 12(73). 628-635. Set./Out.

Viña, J., Borras, C., \& Gomes-Cabrera, M. C. (2018). A free radical theory of frailty. Free Radical Biology and Medicine (124) 358-363. 